\title{
SPECIAL ISSUE ON LEARNING AND TEACHING L2 WRITING
}

\author{
Guest edited by Daphne van Weijen \\ Utrecht University, the Netherlands, \\ Elke Van Steendam \\ Antwerp University, Belgium, \\ and Gert Rijlaarsdam \\ University of Amsterdam, the Netherlands
}

In September 2007, we distributed a call for papers for contributions to ITL International Journal of Applied Linguistics, for a special issue on learning and teaching second language (L2) writing. We were especially interested in studies which included the intercultural component of writing in L2. In addition, we stressed that we wished to include contributions with as many different L2's as possible, not just English. In our European context, we are well aware that English is not the only foreign language taught in education.

We encouraged submissions of papers related to one of three themes. Theme 1 called for theoretical overviews of the relation between $\mathrm{L} 1$ and $\mathrm{L} 2$ writing processes, and theoretical overviews of effective teaching practices in L2 writing education. Theme 2 concerned descriptive empirical studies (qualitative, quantitative) on L2 writing processes, L2 learningto-write processes, the role of L1 in L2 writing and learning processes, backwash effects of $L 2$ learning on $\mathrm{L} 1$ processes and texts. The focus of contributions to this theme had to be on $\mathrm{L} 2$ writing and learning (whatever language L2 might be, certainly not only English), but studies on the relation with $\mathrm{L} 1$, learner characteristics and writing medium were also welcomed. Theme 3 was related to experiments and intervention studies which allow conclusions to be drawn on causal relations between learning environments, course design, experimental lessons and the effect on text quality and/or writing processes. Finally, we also included an extra category in our call for papers: the Writing Board. Contributions to this category had to be short descriptions of effective teaching practices, including a description of the subjects or target audience, intervention, results and experiences.

Initially, we received 34 paper proposals and 7 writing board proposals, which were peer reviewed. Subsequently a blind review procedure was carried out on the full versions of the accepted papers, after which 12 papers and 15 writing board contributions were accepted for publication in this special issue.

Surprisingly, no proposals were submitted related to Theme 1, concerning theoretical overviews of relation between $\mathrm{L} 1$ and $\mathrm{L} 2$ writing and of effective teaching practices in $\mathrm{L} 2$ writing education. We regret this, because we consider it to be a relevant theme in L2 writing research. For example, in their theoretical review of $\mathrm{L} 2$ writing process research, Roca de Larios, Murphy, and Marín (2002) raise a number of issues related to L2 writing which have yet to be investigated in more detail, including: "the notion of L2 writing skill, the formulation process, the temporal character of composition, the cognitive mechanisms involved in the transfer of writing abilities 
across languages, and the situated nature of L2 writing." In addition, recent research has focused on effective teaching practices for teaching writing to adolescents (Graham \& Perin, 2007), but not specifically for L2 writing. In the following sections, we will present and discuss the studies in this special issue related to themes 2 and 3 . Furthermore, we will explain why we chose to include a Writing Board section in this issue and briefly present the contributions that are included in this section.

\section{Theme 2: Descriptive empirical studies}

In our call for papers, we defined theme 2 as: "Descriptive empirical studies (qualitative, quantitative) on L2 writing processes, L2 learning-to-write processes, the role of L1 in L2 writing and learning processes, backwash effects of L2 learning on L1 processes and texts." In all, nine papers specifically related to aspects of theme 2 were accepted for inclusion in this issue, which are all very diverse in nature. First of all, except Margolin and Ezer's study of students writing in Hebrew as L1 or L2 (this issue) and Adams \& Guillot's study of FrenchEnglish Bilingual writers, most of the papers in this theme focus on writing in English as L2. But interestingly participants' first languages differ greatly between studies, including Chinese (Miao \& Lei), Dutch (Lankamp; Van Weijen, Van den Bergh, Rijlaarsdam, \& Sanders), French (Adams \& Guillot; Barbier, Raby, Piolat, \& Roussey), Korean (Lee) and Swedish (Lindgren, Spelman Miller, \& Sullivan), while Ene analyzes a corpus consisting of texts written by writers with rather diverse L1's (Ene, this issue). However in almost all of these studies the focus is on the L2, not on the role of L1 proficiency. Adams and Guillot include vocabulary and spelling measures in both French and English in their analysis, and Lindgren et al include linguistic experience in L1 and L2 in their study. But detailed analyses of the role L1 proficiency might play in L2 writing are not described.

A second distinction that can be made between the papers in this theme is on the basis of their participants. Most of the papers are related to learning or teaching academic L2 writing (Barbier et al.; Ene; Lee; Lankamp; Margolin \& Ezer; Miao \& Lei; Van Weijen et al.) while only a few are related to teaching high school children (Adams \& Guillot; Lindgren et al.). Findings from the studies related to student L2 writers suggest, amongst other things, that L2 writing is a cognitively demanding activity. For example, Barbier et al., report that student writers' cognitive load was highest during note taking from hypertexts in the pen and paper condition in L2, as compared to the other conditions, such as pen and paper writing in L1 or writing on the computer in L1 or L2 (Barbier et al., this issue). Van Weijen et al., (this issue) report that students' writing behaviour appeared rather stable between tasks in L2. This reduction of variation in task execution might also be due to the increase in cognitive load that L2 writing entails.

Adams and Guillot (this issue) focus on the relationship between working memory and writing in bilingual high-school pupils. They conclude that this relationship appears to be domain-specific, as it reflects "the effects of limitations in processing and storage capabilities within the verbal domain". However, they also propose that these verbal processing effects are not language- 
specific. Similarly, Lindgren et al., suggest that learners' concept of text quality is not an L1 or L2 specific concept, but rather a concept which is formed through their writing experience in both $\mathrm{L} 1$ and $\mathrm{L} 2$.

Although these findings are promising, we would encourage future research to focus more on L2 writing in primary and secondary education than on older or more advanced L2 student writers. Bilingualism, or in some regions multilingualism is a dominant characteristic of our global community, with English forming a central part of the set of languages which one needs to be proficient in, in order to function in academic, educational, professional and social situations. Thus, it seems advisable to focus future research on developing and testing pedagogic tools which can be used to teach children to write in languages other than their L1 at an early age. A third and final contrast in L2 writing research which we feel is relevant, is the fact that most studies in this issue focus either on the $\mathrm{L} 2$ writing process (on-line) or on the products or texts produced in L2 (off-line). The studies which focus on the writing process itself often include on-line measures such as keystroke logging (Barbier et al.; Lindgren et al.) and concurrent thinking aloud (Van Weijen et al., this issue). But most of the studies in this theme focus more on off-line product characteristics than on on-line writing processes. Several studies present results of analyses of L2 texts (e.g. Ene; Lankamp; Lee; Miao \& Lei; Margolin \& Ezer), each with a different research focus. In her corpus analysis of advanced ESL graduate students, Ene distinguishes and describes four developmental stages in advanced SLA, and also discusses both positive and negative transfer of $L 1$ textual features. Miao and Lei also discuss the possible role of developmental features and transfer of discourse features from $L 1$ Chinese to English as a foreign language, while Margolin and Ezer suggest that L2 texts written in Hebrew by Arabic students are lower in quality than those written by L1 Hebrew students, due to the fact that Arabic students' L1 rhetorical and linguistic conventions interfere with their L2 writing in Hebrew. Lankamp also focuses on L2 writers' texts, but with a different aim. He hones in on the presence of plagiarism in L2 texts, and suggests that whether writers plagiarize might be influenced more by their lack of knowledge of plagiarism conventions than by a lack of authorial identity. Lee (this issue), on the other hand, concentrates more specifically on learner agency and identity in his case study of a Korean student's struggle to learn how to write in L2 English. He conducted a series of interviews with his student, supplemented by examples of essays and coursework the student wrote, in an attempt to determine how he struggles to learn how to write L2 academic essays. Finally, Adams and Guillot (this issue) attempt to link working memory to writing, by analysing learner characteristics such as working memory skills and language proficiency skills, and text quality.

Only one study, by Van Weijen et al., (this issue) attempts to relate both process and product characteristics, by examining the relations between the occurrence of specific cognitive activities (measured by means of thinking aloud) and the quality of the resulting texts. The results of this study provide some insight into the complex relations between on-line processing and output quality. We think it might be fruitful for theory development to attempt to combine on-line and off-line process and product measures more often in future L2 writing research. 
Editorial

Figure 1. Optimal Variables Research Model for Writing Process Studies

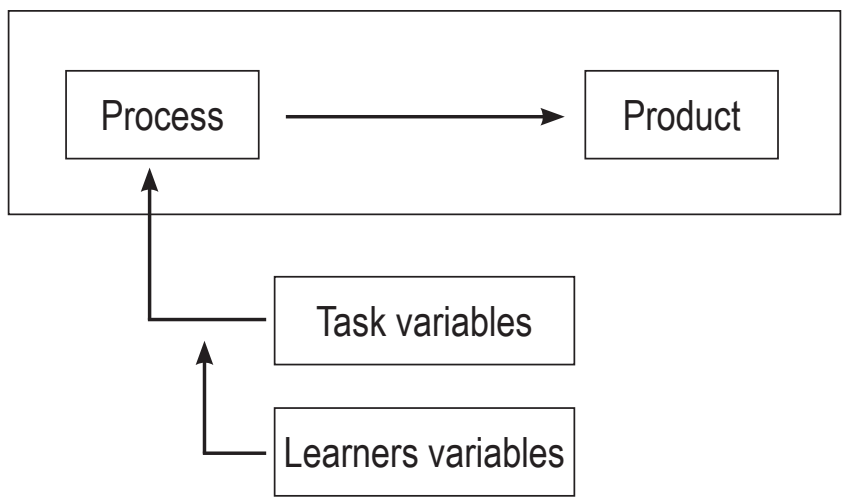

In Figure 1 we present our optimal model for writing process research (see also http://www.

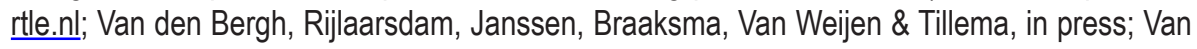
Weijen, 2008). Most writing process studies focus on the writing process, and/or on specific cognitive activities which occur while writing. But the relations between the writing process and the quality of the resulting text have scarcely been studied. Although nowadays more studies on this relation are available (see for example Van Weijen, 2008). Some studies focus on the effect of the task setting (L1 versus L2) within the same writer on specific aspects of the writing process (e.g., Couzijn, Van den Bergh \& Rijlaarsdam, 2002; Stevenson, 2005; Stevenson, Schoonen \& De Glopper, 2006; Uzawa, 1996; Van Weijen, Van den Bergh, Rijlaarsdam \& Sanders, 2008). In rare cases, this task effect is studied in relation to learner characteristics such as L2-proficiency, metacognitive knowledge and fluency (see for example Schoonen, Van Gelderen, De Glopper, Hulstijn, Simis, Snellings, \& Stevenson, 2003). In our opinion, L2- (and L1!) writing process studies would profit from a more complete approach as is depicted in Figure 1.

\section{Theme 3: Experimental and intervention studies}

We defined theme 3 in our call for contributions as "Experiments and intervention studies that allow conclusions about causal relations between learning environments, course design, experimental lessons and the effect on text quality and/or writing processes." We accepted three experimental studies for this issue. These studies allow causal inferences to be drawn related to the interventions tested and the output variable, in all instances indicators of writing proficiency. Remarkably, none of the studies included measures of writing processes in their research design. We suggest that future L2-writing education studies should include writing process measures for two reasons. First of all, including writing processes as dependent variables makes it possible to analyse the kind of aspects of the writing process that are affected by various interventions in greater detail (See for an example in L1-writing research Braaksma, 
Rijlaarsdam, Van den Bergh, \& Van Hout-Wolters, (2004) in Cognition and Instruction, using think aloud protocols, and Torrance, Fidalgo, \& Garcia (2007), using online self reports). Second, when experimental studies include writing processes and text quality in the research design, the relation between processes and text quality can be studied, which helps us to refine theories on effective writing processes (see Braaksma, et al., 2004).

The three experimental papers in this issue focus on English as L3 (Van Beuningen, De Jong \& Kuiken), French as L2 (Mills \& Péron) and English as L2. The settings are quite different, varying from more traditional (Mills and Péron, students (English as L1) taking a course in a foreign language (French)), to multilingual settings (Van Beuningen et al., with English as L3), to deaf students (sign language as L1) learning to write in English (as L2) in Wolbers.

In a study with 14-year old multilingual students, Van Beuningen, De Jong and Kuiken (this issue) compared the effectiveness of direct and indirect corrective feedback to the effect of two control treatments: a treatment that offered students an extra opportunity to practice their writing skills, and a treatment in which students self-corrected their errors without any available feedback. Results show that only direct feedback proved to have a significant long-term effect. Neither of the control treatments had a significant effect on students' accuracy.

Mills and Péron (this issue) evaluated how global simulation influenced the development of students' writing self-efficacy and text quality in intermediate French. Significant differences were found in L2 students' of French self-efficacy beliefs, writing self-concept, writing anxiety, and text quality in organization, content, and creativity after participation in a global simulation curriculum, but not on lower order skills.

Wolbers (this issue) investigated the effects of using Strategic and Interactive Writing Instruction (SIWI) with deaf, middle school students who use American Sign Language as their L1 and written English as L2. Students receiving SIWI made significantly greater gains compared to those who did not receive SIWI on higher and lower order writing skills, in the target genre but also in a non-taught genre.

Of these three studies, two interventions (Mills \& Péron; Wolbers) also seem to fit well within the L1 writing curriculum. The studies are bound to the L2-domain in only one respect. In fact, only the description of the participants in the studies indicates that they are L2-studies, all other components are not language specific. This is an interesting phenomenon: L1-writing and L2-writing intervention studies may have a lot in common. The simulation approach (Mills \& Péron) has been applied fairly frequently in L2-oral skills training, and is now introduced in writing in $\mathrm{L} 2$, but is certainly also applicable in $\mathrm{L} 1$ writing. The SIWI approach which has, until now, been applied in various formats in L1 settings, is now implemented by Wolbers in an L2 setting. Key features of successful learning arrangements in L1 and L2 might well be the same: rich contexts, strategy oriented, stimulating interaction and involvement. Furthermore, we also know that writing processes in L1 and L2 have much in common, that the L2-process relates strongly to the L1-process, and that the quality of writing in L1 (text quality) can be predicted to some extent based on students' L2-writing behaviour (Van Weijen et al., 2008). This is quite surprising: knowing one's L2-writing behaviour helps to predict the L1-text quality, while the reverse does not work: writers' $L 1$ writing processes do not appear to have any predictive power for L2-text quality. That is due partly to the fact that writers' approach to L2 writing appears to 
be far more stable between tasks than in L1. But the extent to which L2-proficiency influences both the writing process and L2 text quality is unclear. Therefore, future L2-writing studies could include two additional features to enrich the theory. First of all, the L1 and L2 characteristics (initial writing skills, linguistic proficiency) of the participants could be taken into account in the design. Recent dissertation studies that explored aptitude treatment interactions all found relevant interactions, indicating that some interventions are better for weaker students, while other interventions are more effective for stronger students (for L1: Braaksma, 2002; Kieft, 2006; Raedts, 2008; and for L2: Van Steendam, 2008). These characteristics can also have an effect on the most effective format of an intervention: Van Steendam (2008) for example shows that modelling as an instructional method to teach students to improve their revision and writing skills is more effective for (initially) more competent L2 writers compared to weaker writers. Additionally, the researchers also reports that especially strong, homogeneous dyads with two more proficient writers seem to benefit more from observation while revising collaboratively than weak, heterogeneous dyads. Taking into account the language variable in L2 studies might reveal that L1-oriented instructional approaches work for a specific group of students, not for all. A second addition we suggest for future studies is the measurement of L1-writing skill, not only as an initial learner characteristic, but also as a dependent variable. If writing in L2 depends on L1-writing, and L2-writing is the target of instruction, then one may assume that effective instruction in L2 writing, for example through feedback (Van Beuningen et al.), simulation (Mills \& Péron) or strategy oriented interactive instruction, will not only affect $L 2$ writing but also L1 writing.

In Figure 2 we present our optimal variables model for intervention studies (see also http://www.

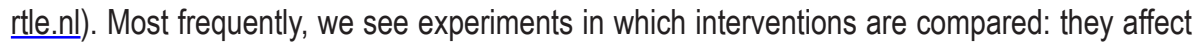
the end product (text quality) differently. What we would like to add are two other measures (intermediate variables): writing process, and learner characteristics, under the assumption that the effect of the interventions is different for different types of learners. In the case of L2-writing studies, we would like to also include L1, both as a learner characteristic and as an output variable.

Figure 2. Optimal Variables Model for Intervention Studies

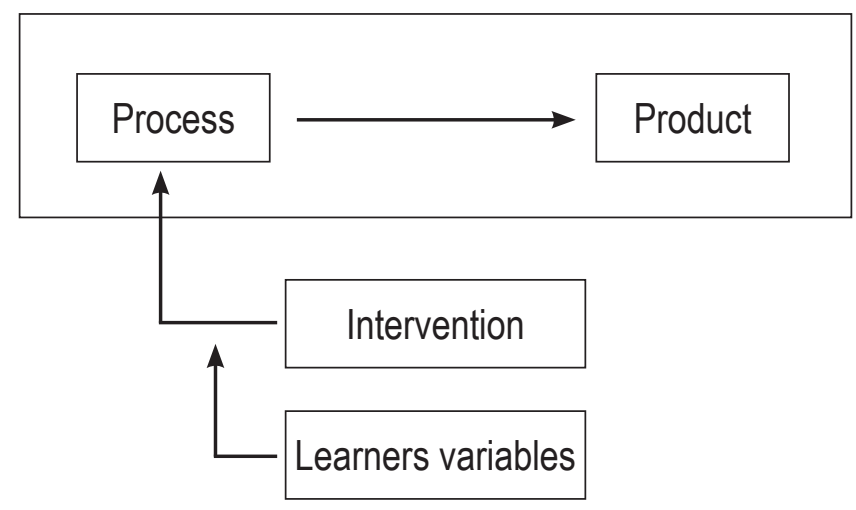




\section{Writing Board papers}

When we prepared this special issue, we thought it would be a good idea to collect Writing Board texts, short descriptions of effective teaching practices or descriptions of research findings which have direct relevance for the L2 writing classroom. The focus is mainly on the content and structure of the intervention, with some context (student characteristics) and sometimes more general thoughts on effects. We decided to include this category which focuses on classroom best practices in an attempt to trigger future research initiatives which focus more directly on the implementation and effectiveness of educational interventions. These writing board texts will hopefully encourage researchers to include best practices in their interventions and might inspire other teachers to adapt some of the ideas to their own teaching practice. The relatively large number of responses that our call generated suggests that many teachers do not suffer from a lack of good ideas regarding educational interventions, but more from a lack of time to carry out research related to the implementation of such new pedagogical tools. That is a pity, because in our view the L2 writing field would benefit greatly from studies which manage to combine research and teaching in an educational setting. An interesting methodological development in this respect is the development of design research. In this type of research, series of lessons are designed, tested and redesigned in order to further adapt them for educational purposes. This sequence of designing, testing, and improving is repeated in different contexts until all those concerned (teachers and researchers) are satisfied with the results (see for example Van den Akker, Branch, Gustafson, Nieveen \& Plomp, 1999; and also Rijlaarsdam, Van den Bergh, \& Couzijn, 2004; for examples related to L1 writing research). The main advantage of this type of research is that teachers are actively involved in the research process and that the research takes place in realistic classroom settings. Another advantage is the fact that design studies often focus on solving real-life educational problems, which means that the outcome of such studies is highly relevant for educational practices.

In the writing board section, we included interventions and practices which reported on learning arrangements the authors created themselves often with one group of students (which they often followed for a longer period of time). These intervention studies were included in the writing board section, instead of in the paper section with empirical intervention studies, as they often do not include a control or comparison group or a statistical quantification of the dependent variables. The learning arrangements the authors created, even if they were not always embedded in an educational theoretical concept, offer interesting insights in effective educational approaches especially as they are often based on long-term teaching experience. The WB-papers had to be kept very short. One exception was made for Haiyong Liu who published personal experience in what we call a personal essay. We created a bit more space for this study because of the important characteristic of the students involved in the researcher's classes: students with another language background than the standard language, studying their $\mathrm{L} 1$. This is a language learning situation which occurs more and more frequently all over the world as a result of global migration: heritage learners, as Haiyiong Liu calls them, deserve extra attention when setting up language learning situations. Haiyiong Liu's analysis of the students' strengths and weaknesses in their L1 is an interesting step in the needs analysis 
phase in curriculum design. He analyzes and characterizes his bilingual Chinese-English students as semi-native writers. While English is their dominant language, these students from Chinese speaking families speak Chinese fluently, but the quality and nature of their writing is far from native Chinese. In a personal essay, Liu describes his instructional approaches to improve the writing skills of this group of Chinese students.

The majority of the Writing Board papers included in this issue focus on (advanced) academic L2 writing albeit in different ways (Crespo \& Vangehuchten; Curry \& Lillis; Lake; Lau; Lehrer; Miller-Cochran; Murphy; O'Keefe; Pastor; Strauss; Waterstone; Whitley \& Grous; all this issue). But there are also contributions concerned with the teaching of L2 writing to young children (Flynn, this issue), and high school L2 writing (Taura, this issue). Although we explicitly invited contributions related to writing in any second or foreign language, most of the contributions in this special issue are related to writing in English as L2 or L3 (except Adams \& Guillot; Crespo \& Vangehuchten; Liu; Margolin \& Ezer; Mills \& Péron; this issue). This is understandable, given the widespread use of English as lingua franca. However, we would encourage further research on L2 writing to extend beyond the ESL/EFL boundaries and include research on L2 writing in other linguistic contexts as well. We do not comment on all the WB-papers we included in this issue, but confine our discussion to a brief introductory list of all contributions in alphabetical order.

Manuela Crespo \& Lieve Vangehuchten describe a course for Belgian Business and Economics students learning Spanish based on task based learning approaches. They conclude that their portfolio experience clearly enhances creative and authentic writing, stimulates essential skills for Lifelong learning and self-evaluation, and leaves plenty of room for additional activities and personal input. Also, this exercise has proven to be extremely motivating, both in content and in form. And as we all know, motivation is the key to any kind of learning.

Mary Jane Curry and Theresa Lillis focus on the problems $L 2$ writers encounter during academic writing and publishing. They present and briefly discuss the research-based heuristics that they designed to aid L2 writers who are trying to publish their work in English.

Naomi Flynn describes a case study in which Bridget, an inner-city school teacher was observed during several writing lessons that she taught to a group of 6/7 year old children. The focus of this contribution is on the methods Bridget employed, such as a strong focus on oracy, in an attempt to help her pupils learn to write.

Morgan Lake describes his structured approach for learners of Asian English as L2. One of the challenging components he describes is: "Raising the difficulty level of cognitive and emotional challenge (not i +1 , but more like i +100 ) delivered more accurate mechanics".

Ken Lau presents an approach to teaching cohesion in writing to Honk Kong ESL students: cognitive apprenticeship. He explains why cognitive apprenticeship is an appropriate tool for teaching cohesion in an ESL setting and describes the stages that occur during a typical lesson using this method. 
Stephanie Lehrer discusses the strong link between efficient reading comprehension and $L 2$ writing. She describes how she taught her students to annotate the texts they had to read for an EAP (English for Academic Purposes) reading comprehension course and the beneficial effects that teaching this strategy appeared to have.

Susan Miller-Cochran describes a group conference strategy to enable peers to discuss their texts. She concludes that when implemented throughout the semester, this strategy helps students to build confidence in communicating their suggestions for revision.

Terence Patrick Murphy describes how he teaches South-Korean students to write attractive introductions, adapting John Swales' Genre Analysis theory, in what he calls, a TINA Method. This method allows EFL students to understand the reasons for their intuitive sense of unease. With sufficient training, writers can then use the TINA Method to choose among the variety of options for improving their writing.

Meaghan O'Keefe describes a solution to a specific problem she encountered while teaching English composition in Qatar in the Middle East. The students she taught were required to write college admission essays, but their L2 essays were often lacking in style. O'Keefe describes how she helped students improve their writing style by introducing them to Greek and Roman rhetorical figures of repetition.

Maria Luisa Carrio-Pastor describes a course in which Spanish engineering students learn English in a content focussed project, together with content and language teachers.

Pat Strauss focuses on the fact that L2 students are still learning the language in which they are required to write their theses or dissertations. As a result they are subject to the anxiety and insecurity common to all language learners. As a language adviser she followed two dissertation students and their supervisor. Her advice is to use larger supervisory teams involving staff with different areas of expertise such as experience in second language teaching.

Hideyuki Taura examines how 16 Japanese expatriate students who return to Japan from English speaking countries retain their L2 writing skills. When students receive the first four years of literacy education in $L 2$, this has a positive influence on the complexity of their written texts and on the choices made in using more sophisticated vocabulary items.

Bonnie Waterstone works from an understanding of academic literacies as "socially situated discourse practices which are ideologically inscribed" (Lillis, 2003, p.194). She has been developing and teaching a course designed to prepare international ESL writers for graduate level study in a Masters of Education in Teaching English as a foreign or second language (TEFL/ESL). One of her main goals was to encourage critical analysis of scholarly work through writing critical summaries. Introducing the concept of multi-competence (i.e., that L2 language knowledge is greater than that of monolinguals) helped students recognize their strengths as 
Editorial

L2 users and to value their own contributions to the scholarly discourse communities they were joining.

Edgar Whitley and Alexander Grous describe a project in which they followed students with heterogeneous backgrounds, writing critical literature reviews. The study will help the teachers of the next cohort of students to reflect on their current teaching practices and to share strategies for addressing the concerns of both home and international students in undertaking the assignment and improving awareness of the various support services available to them.

Overall, the papers and Writing Board contributions in this issue provide an interesting mix of research findings and practical teaching practices related to $L 2$ writing, which we hope will inspire both further research and further educational improvements. 
Braaksma, M. A. H. (2002). Observational learning in argumentative writing. Amsterdam: Graduate School for Teaching and Learning, University of Amsterdam.

Braaksma, M.A.H., Rijlaarsdam, G., Van den Bergh, H., \& Van Hout-Wolters, B.H.A.M. (2004). Observational learning and its effects on the orchestration of writing processes. Cognition and Instruction, 22(1), 1-36.

Graham, S., \& Perin, D. (2007). A meta-analysis of writing instruction for adolescent students. Journal of Educational Psychology, 99(3), 445 - 476.

Kieft, M. (2006). The effects of adapting writing instruction to students' writing strategies. Amsterdam: Graduate School for Teaching and Learning, University of Amsterdam.

O'Brien, T. (2004). Writing in a foreign language: teaching and learning. Language Teaching, $37,1-28$.

Rijlaarsdam, G., \& Van den Bergh, H. (2004). Effective Learning and Teaching of Writing: Student involvement in the teaching of writing. In G. Rijlaarsdam (Series Ed.), G. Rijlaarsdam, H. v. d. Bergh \& M. Couzijn (Vol. eds.), Studies in Writing Vol. 14, Effective Learning and Teaching of Writing (2 ed., pp. 1 - 16). Dordrecht: Kluwer Academic Publishers.

Roca de Larios, J., Murphy, L., \& Marín, J. (2002). A critical examination of L2 writing process research. In G. Rijlaarsdam (Series Ed.), S. Ransdell \& M. L. Barbier (Vol Eds.), Studies in Writing Vol. 11, New directions for research in L2 writing (pp. 11 - 47): Dordrecht: Kluwer Academic Publishers.

Schoonen, R., Van Gelderen, A., De Glopper, K., Hulstijn, J., Simis, A., Snellings, P., \& Stevenson, M. (2003). First language and second language writing: the role of linguistic knowledge, speed of processing and metacognitive knowledge. Language Learning, 53(1), 165 - 202.

Stevenson, M. (2005). Reading and writing in a foreign language; a comparison of conceptual and linguistic processes in Dutch and English. SCO-Kohnstamm Instituut van de Faculteit der Maatschappij- en Gedragswetenschappen, University of Amsterdam, Amsterdam.

Stevenson, M., Schoonen, R., \& De Glopper, K. (2006). Revising in two languages: A multidimensional comparison of online writing revisions in L1 and FL. Journal of Second Language Writing, 15, 201-233.

Torrance, M., Fidalgo, R., \& García, J.-N. (2007). The teachability and effectiveness of cognitive self-regulation in sixth-grade writers. Learning and Instruction, 17(3), 265-285.

Uzawa, K. (1996). Second language learners' processes of L1 writing, L2 writing and translation from L1 into L2. Journal of Second Language Writing, 5(3), 271-294.

Van den Akker, J., Branch, R., Gustafson, K., Nieveen, N., \& Plomp, Tj. (Eds.) (1999). Design approaches and tools in education and training (pp. 125-136). Dordrecht: Kluwer Academic Publishers.

Van den Bergh, H., Rijlaarsdam, G., Janssen, T., Braaksma, M., Van Weijen, D., \& Tillema, M. (in press). Relating process execution to writing, reading and output quality of text: consideration learner and task characteristics. In M. C. Shelley II, L. D. Yore \& B. Hand (Eds.), Quality research in literacy and science education: International perspectives and gold standards. Dordrecht, The Netherlands: Springer.

Van Steendam, E. (2008). Effective instructional strategies in collaborative revision: Two empirical studies. Unpublished doctoral dissertation, University of Leuven, Belgium. 
Van Weijen, D. (2009), Writing processes, text quality, and task effects (Vol. 201). Utrecht: LOT.

Van Weijen, D., Van den Bergh, H., Rijlaarsdam, G., \& Sanders, T. (2008). The effect of writing in $L 1$ versus $L 2$ on process-product relations. Manuscript submitted for publication. 